\title{
Possible application of animal fat as engine fuel - lubricity aspects
}

\begin{abstract}
The paper presents results of animal fat lubricity test performed at high frequency reciprocating rig (HFRR). Impact of test temperature on wear scar diameter (WSD) is shown. Results for animal fat are compared with those for mineral diesel fuel (ULSD). Obtained WSD prooved excellent lubricating properties of animal fat. Laboratory test results are backed up with engine trials where two sets of fuel pumps were tested on a large reciprocating engine. Animal fat can be used as fuel for engines when appropriate filtration process is implemented.
\end{abstract}

Key words: animal fat, tallow, lubricity, HFRR

\section{Zastosowanie tluszczu zwierzęcego jako paliwa - aspekty smarności}

Wartykule zaprezentowano wyniki badań smarności przeprowadzonych z użyciem aparatu o ruchu posuwisto-zwrotnym wysokiej częstotliwości (HFRR). Przedstawiono wplyw temperatury paliwa na średnicę śladu zużycia (WSD). Wyniki otrzymane dla tluszczu zwierzęcego porównano z wynikami dla oleju napędowego. Zmierzone średnice śladu zużycia potwierdzają dobre właściwości smarne tluszczu zwierzęcego. Wyniki testów laboratoryjnych potwierdzono testami silnikowymi, w których dwa zestawy pomp wtryskowych przetestowano na dużym silniku wysokoprężnym. Thuszcze zwierzęce moga być stosowane jako paliwa silnikowe pod warunkiem przeprowadzenia odpowiedniego procesu filtracji.

Słowa kluczowe: tluszcz zwierzęcy, smarność, HFRR

\section{Introduction}

Growing concerns regarding availability of fossil fuels led to intensive search for alternative fuels for reciprocating engines. Extensive research programmes were conducted to investigate suitability of neat triglycerides, particularly crude palm oil (CPO) or straight vegetable oil (SVO) as engine fuels.

Animal fat is sourced from waste material such as animal carcasses or food waste, therefore no agricultural crop (i.e. corn, soybean, and rapeseed) is used in the production process. Due to its high calorific value and low sulphur content it may be considered for power generation applications especially for installations located at rendering plants. However, difference in physical properties and in chemical composition accompanied with presence of impurities remaining after rendering process require detailed analysis of animal fat impact on fuel supply system.

A Knowledge Transfer Partnership programme between The University of Birmingham and John Pointon \& Sons Ltd. - one of the leaders in UK rendering market had as one of its aims an assessment of the suitability of tallow as fuel for internal combustion engines.

\section{Literature review}

Verification of lubricating properties initially applied only to fuels used in aviation industry [1]. Introduction of low sulphur diesel fuels resulted in fuel injection pumps and distributor pumps failures, particularly in Sweden [2]. Low sulphur fuels possess poorer lubricity than nondesulphurised, mainly due to removal of polar oxygen and nitrogen containing compounds [3, 4].

\section{Wprowadzenie}

Kurczenie się zasobów paliw kopalnych skłania do intensywnych poszukiwań alternatywnych paliw do silników tłokowych. Stworzono programy badawcze mające na celu sprawdzenie możliwości wykorzystania tłuszczy - trójglicerydów, szczególnie oleju palmowego (CPO), jak również olejów roślinnych (SVO).

Tłuszcz zwierzęcy otrzymywany jest z materiałów odpadowych, takich jak uboczne produkty pochodzenia zwierzęcego czy odpady spożywcze; a więc w procesie produkcyjnym nie wykorzystuje się płodów rolnych. Ze względu na wysoką wartość opałową i niską zawartość siarki, tłuszcz może stanowić atrakcyjne paliwo alternatywne w zastosowaniach energetycznych, szczególnie w elektrowniach zlokalizowanych w zakładach przemysłu mięsnego i utylizacyjnego. Odmienne właściwości fizyczne i skład chemiczny oraz obecność zanieczyszczeń, będących pozostałością procesu produkcyjnego (rendering), wymagają dokładnej analizy oddziaływania tłuszczu na elementy układu paliwowego.

Badania zrealizowano $\mathrm{w}$ ramach programu badawczego (Knowledge Tranfer Partnership) ustanowionego pomiędzy Uniwersytetem Birmingham a John Pointon \& Sons Ltd. - jedną z największych firm sektora utylizacji odpadów w Wielkiej Brytanii. Celem programu było zbadanie przydatności tłuszczu zwierzęcego jako paliwa do silników tłokowych.

\section{Literatura}

Sprawdzanie właściwości smarnych początkowo dotyczyło tylko paliw lotniczych [1]. Wprowadzenie paliw do silników wysokoprężnych o obniżonej zawartości siarki spo- 
Several methods have been developed to assess fuel lubricity. These include: the Scuffing Load Ball on Cylinder Lubricity Evaluator (SLBOCLE), the High-Frequency Reciprocating Rig (HFRR), and the Ball on Three Seats (BOTS). More detailed description and discussion of correlation between full scale injection pump systems and laboratory methods can be found in [1].

Products of triglycerides transesterification process are regarded to be good lubricity enhancers, especially when blended at level of 1-2\% with ULSD [4-6].

Lubricity of neat fatty compounds depends on various features such as saturation, oxygen presence, number of $\mathrm{OH}$ groups [4].

\section{Research programme}

Description of animal fat properties and production process is presented in one of authors' papers [7]. Investigation focused on properties consistency. Despite acidity variation associated with ambient temperature influencing decomposition process, other properties presented some level of consistency enabling stating set of typical values for animal fat. Next step was to establish limits - internal specification when fuel would be rejected and not used for engine trials.

Fuel sample, properties of which are close to typical (Tab. 1), has been tested using HFRR to analyse its lubricity at various temperatures. Test was performed to verify if fat treated in usual way - filtered and washed and complying with internal specification, will have lubricating properties good enough to be used in diesel injection systems.

Due to its high viscosity, animal fat has to be preheated above $75 \mathrm{degC}$. Therefore lubricity test conditions must be altered to reflect real conditions. wodowało usterki pomp wtryskowych oraz dystrybutorów paliw, szczególnie w Szwecji [2]. Paliwa o niskiej zawartości siarki charakteryzują się gorszymi właściwościami smarnymi od paliw niemodyfikowanych, głównie z uwagi na brak składników zawierających tlen i azot.

Wprowadzono kilka metod oceny smarności paliw, takich jak: metoda SLBOCLE (Scuffing Load Ball on Cylinder Lubricity Evaluator), metoda HFRR (High Frequency Reciprocating Rig), czy też metoda BOTS (Ball on Three Seats). Szczegółowy opis metod oraz dyskusja zgodności wyników otrzymanych przy zastosowaniu metod laboratoryjnych z wynikami testów zużycia pomp wtryskowych dostępne są w pracy [1].

Produkty procesu estryfikacji trójglicerydów uważane są za dodatki polepszające smarność paliw, szczególnie gdy ich udział w mieszaninie z olejem napędowym (ULSD) wynosi $1-2 \%$ [4-6].

Smarność paliw tłuszczowych zależy od takich cech, jak: nasycenie, obecność tlenu, zawartość grup $\mathrm{OH}$ [4].

\section{Program badawczy}

Opis właściwości tłuszczów zwierzęcych oraz procesu produkcyjnego zawarto we wcześniejszej publikacji autorów tego artykułu [7]. Badania miały na celu sprawdzenie, czy właściwości tłuszczu, mającego stanowić paliwo silnikowe, pozostają stałe. Wykryto zależność kwasowości paliwa od temperatury otoczenia. Inne badane parametry pozostały względnie stałe, co umożliwiło autorom określenie typowych właściwości tłuszczu. Następnym krokiem było ustanowienie wewnętrznej specyfikacji dla paliwa służącego do testów silnikowych.

Próbka paliwa (czysty tłuszcz zwierzęcy) o właściwościach zbliżonych do typowych (tab. 1), została przetestowa-

Table 1. Animal fat typical specification, tested sample properties Tabela 1. Właściwości tłuszczu zwierzęcego: typowe oraz badanej próbki

\begin{tabular}{|l|c|c|c|c|}
\hline Data series/dane & $\begin{array}{c}\text { Annual average/ } \\
\text { średnia roczna }\end{array}$ & Limit & $\begin{array}{c}\text { Sample/ } \\
\text { badana próbka }\end{array}$ & $\begin{array}{c}\text { Unit/ } \\
\text { jednostka }\end{array}$ \\
\hline $\begin{array}{l}\text { Moisture/zawór } \\
\text { wody }\end{array}$ & 0.28 & 0.5 & 0.16 & $\%$ \\
\hline $\begin{array}{l}\text { Insoluble impurities/ } \\
\text { zanieczyszczenia }\end{array}$ & 0.13 & 0.4 & 0.15 & $\%$ \\
\hline Ash/popioty & 0.04 & 0.1 & 0.06 & $\%$ \\
\hline $\begin{array}{l}\text { Iodine value/liczba } \\
\text { jodowa }\end{array}$ & 50.9 & 55 & 54 & $\mathrm{gI}_{2} / 100 \mathrm{~g}$ \\
\hline $\begin{array}{l}\text { Polyethylene/poli- } \\
\text { etylen }\end{array}$ & 13.7 & 35.0 & 15 & $\mathrm{ppm}$ \\
\hline
\end{tabular}

Paper also presents effects of using fuel not complying with defined specification.

\section{Test equipment}

\subsection{HFRR - High Frequency Reciprocating Rig}

The rig has been supplied by PCS Instruments Ltd. London, UK. Schematic diagram showing the working principle is given in Fig. 1. Technical specification is given in Table 2. standardowa $\left(60^{\circ} \mathrm{C}\right)$ temperaturę paliwa. na przy użyciu aparatu HFRR, w celu sprawdzenia właściwości smarnych w różnych temperaturach. Celem testów była weryfikacja hipotezy, iż paliwo poddane procesowi filtracji, spełniające wymagania normy wewnętrznej, będzie wykazywało właściwości smarne wystarczające do zastosowania w silniku wysokoprężnym - porównywalne lub przewyższające olej napędowy.

Ze względu na dużą lepkość tłuszcz musi być podgrzany do temperatury wyższej niż $75^{\circ} \mathrm{C}$. Warunki badania HFRR zostały zmodyfikowane, aby uwzględnić wyższą niż W tej publikacji przedstawiono również skutki stosowania paliwa niespełniającego normy wewnętrznej.

\section{Aparatura badawcza}

\subsection{HFRR - High Frequency Reciprocating Rig}

Stanowisko badawcze dostarczyła firma PCS z Londynu. Schemat ilustrujący zasadę jego działania przedstawiono na rys. 1 . Specyfikacje podano w tabeli 2. Aby zwiększyć 
To increase test repeatability and reduce scatter the rig has been fitted with temperature and humidity controlled cabinet so test can be carried out at constant temperature and relative humidity. Wear scar diameter is measured with Meiji metallurgical microscope equipped with digital measurement camera. Test conditions were based on ISO 12156 standard (refer to Tab. 3).

Certified specimens provided by PCS were used for testing. The upper specimen is a $6.00 \mathrm{~mm}$ diameter ball that is loaded into the upper specimen holder. The upper specimen is specified to grade 28 (ANSI B3.12), ANSI E-52100 steel, with a Rockwell hardness "C" scale (HRC) number of 58-66 (ISO 6508), and a surface finish of less than $0.05 \mu \mathrm{m} \mathrm{Ra}$. The lower specimen is a disc that is loaded into the lower specimen holder. The lower specimen is specified to ANSI E-52100 steel machined from annealed rod, with Vickers hardness "HV30" scale number of 190-210 (ISO 6507/1). It is turned lapped and polished to a surface finish of less than $0.02 \mu \mathrm{m} \mathrm{Ra}$ [9].

Table 2. PCS HFRR technical specification

Tabela 2. Dane techniczne aparatu HFRR produkcji PCS

\begin{tabular}{|l|c|}
\hline Frequency/częstotliwość & $10-200 \mathrm{~Hz}$ \\
\hline Stroke/skok & $20 \mu \mathrm{m}-2.0 \mathrm{~mm}$ \\
\hline Load/obciążenie & $0-1.0 \mathrm{~kg}$ \\
\hline Max. friction force/max. siła & $10.0 \mathrm{~N}$ \\
\hline Temperature/temperatura & Up to $400 \mathrm{degC}$ \\
\hline Upper specimen/próbka górna & $6.0 \mathrm{~mm}$ diameter ball \\
\hline $\begin{array}{l}\text { Lower specimen/próbka dolna } \\
\text { Camera resolution/rozdzielczość } \\
\text { obrazu kamery }\end{array}$ & \begin{tabular}{c} 
disc $3.0 \mathrm{~mm}$ thick \\
\hline
\end{tabular} \\
\hline
\end{tabular}

\subsection{Fuel Pumps}

Two sets of Ruston FAR 20000 fuel pumps (shown in Fig. 2) have been installed on Ruston 6AR engine. Technical data are given in Table 4. Fuel pumps were inspected daily for leaks. Each set was used for approximately $1000 \mathrm{~h}$.

Table 4. Fuel pump specification

Tabela 4. Dane techniczne pompy wtryskowej

\begin{tabular}{|l|c|}
\hline Pump type/typ pompy & FAR - 20000 \\
\hline $\begin{array}{l}\text { Camshaft speed/prędkość obr. } \\
\text { watka rozrzqdu }\end{array}$ & $300 \mathrm{rpm}$ \\
\hline Pump stroke/skok & $15 \mathrm{~mm}$ \\
\hline Plunger diameter/średnica tłoczka & $22 \mathrm{~mm}$ \\
\hline $\begin{array}{l}\text { Fuel delivery at full load/objętość } \\
\text { paliwa max. obc. }\end{array}$ & $200 \mathrm{~cm}^{3} / 100$ strokes \\
\hline $\begin{array}{l}\text { Injector nozzle configuration/ } \\
\text { konfiguracja dyszy wtryskiwacza }\end{array}$ & $10 \times 0.014$ " \\
\hline $\begin{array}{l}\text { Injector release pressure/ciśnienie } \\
\text { otwarcia wtryskiwacza }\end{array}$ & $200 \mathrm{bar}$ \\
\hline
\end{tabular}

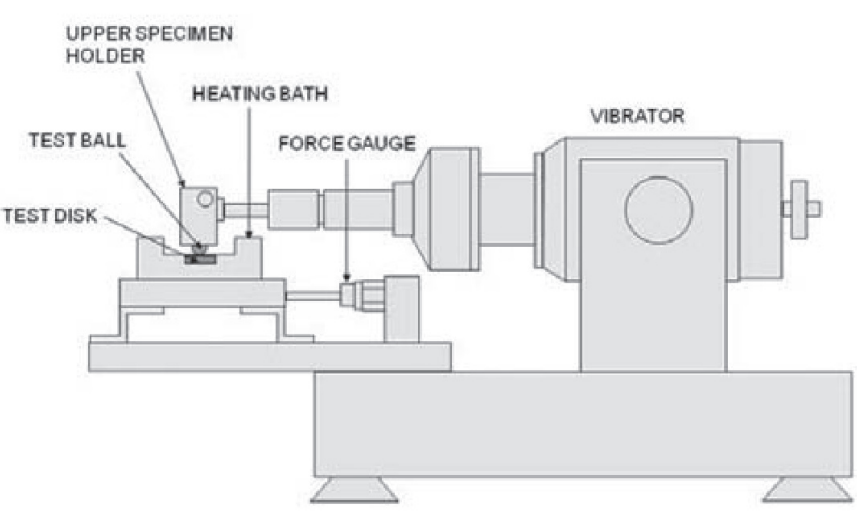

Fig. 1. Schematic diagram of HFRR [1]

Rys. 1. Schemat aparatu HFRR [1]

powtarzalność uzyskiwanych wyników, stanowisko wyposażono w szczelną komorę umożliwiającą prowadzenie badań przy zadanej temperaturze i wilgotności powietrza. Średnice śladu zużycia zmierzono przy użyciu mikroskopu metalograficznego Meiji wyposażonego w kamerę cyfrową. Warunki przeprowadzenia testu, podane w tabeli 3, bazowały na podanych w normie ISO 12156.

Do badań użyto zestawów testowych certyfikowanych przez PCS. Próbkę górną stanowi kulka o średnicy $6 \mathrm{~mm}$, umieszczana w uchwycie górnym. Kulka powinna być wykonana ze stali 28 (ANSI B3.12), ANSI E-52100, o twardości Rockwella HRC 58-66 (ISO 6508) i chropowatości powierzchni Ra poniżej 0,05 $\mu \mathrm{m}$. Próbkę dolną stanowi dysk, który umieszcza się w uchwycie dolnym. Dysk powinien być wykonany ze stali ANSI E-52100 o twardości Vickersa HV30 190-210 (ISO 6507/1). Powierzchnia powinna być polerowana do uzyskania chropowatości Ra mniejszej niż $0,02 \mu \mathrm{m}[9]$.

Table 3. Test condition based on ISO 12156

Tabela 3. Warunki testu na podstawie ISO 12156

\begin{tabular}{|l|c|}
\hline $\begin{array}{l}\text { Fluid volume/objętość próbki } \\
\text { paliwa }\end{array}$ & $2 \pm 0.2 \mathrm{ml}$ \\
\hline Stroke length/dlugość skoku & $1 \pm 0.002 \mathrm{~mm}$ \\
\hline Frequency/częstotliowść & $50 \pm 1 \mathrm{~Hz}$ \\
\hline $\begin{array}{l}\text { Fluid temperature/temperatura } \\
\text { plynu }\end{array}$ & $60,75,90 \pm 2 \mathrm{degC}$ \\
\hline Applied load/obciążenie & $200 \pm 1 \mathrm{~g}$ \\
\hline Test duration/czas testu & $75 \pm 0.1 \mathrm{~min}$ \\
\hline $\begin{array}{l}\text { Bath surface area/powierzchnia } \\
\text { zbiornika plynu }\end{array}$ & $6 \pm 1 \mathrm{~cm}^{2}$ \\
\hline
\end{tabular}

\subsection{Pompy wtryskowe}

Do badań użyto dwóch zestawów zawierających sześć sztuk pomp wtryskowych FAR 20000 (rys. 2) zainstalowanych na silniku Ruston 6AR. Dane techniczne podano w tabeli 4. Przeprowadzano codzienne rutynowe kontrole wycieków paliwa. Każdy zestaw testowano przez około 1000 godzin. 

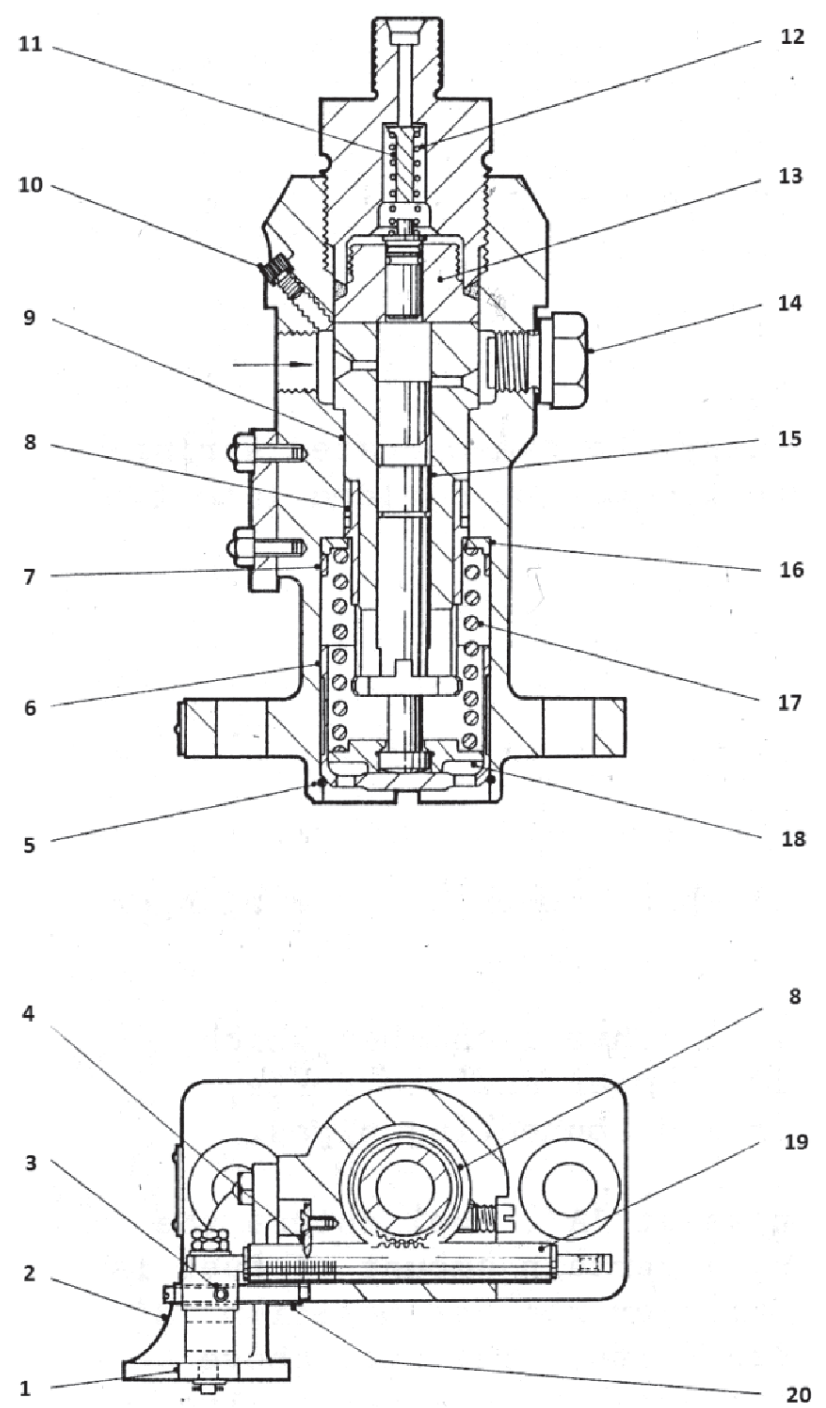

Fig. 2. Assembly of fuel pump: 1 - control rack slipper, 2 - rack support bracket, 3 - lead sealed grubscrew for 20, 4 - setting pointer, 5 - tappet retaining ring, 6 - plunger tappet, 7 - spring ring, 8 - operating pinion, 9 - plunger guide, 10 - air vent plug, 11 - delivery valve stop, 12 - delivery valve spring, 13 - delivery valve assembly, 14 - spill plug, 15 - plunger, 16 - upper spring collar, 17 - plunger spring, 18 - lower spring collar, 19 - operating rack, 20 - overload stop screw [2]

Rys. 2. Elementy pompy paliwa: 1-stojak obrotowy, 2-wspornik, 3 - blokada, 4-wskaźnik ustawienia, 5 - pierścień popychacza, 6-tłok popychacza, 7 -pierścień, 8-koło zębate, 9-tłok, 10-zawór odpowietrzający, 11 -zawór odcinający, 12 - sprężyna, 13 -element montażowy zaworu, 14 - korek, 15 - tłok, 16-górny kotnierz sprężyny, 17 - sprężyna, 18 - dolny kotnierz sprężyny, 19 -zębatka, 20-element przeciażeniowy [2]

\section{Results and discussion}

\subsection{HFRR}

Test for each temperature has been repeated three times, calculated averages are reported in Table 5.

Wear scar measured for ULSD is shown in Fig. 3. Measured diameter of $320 \mu \mathrm{m}$ is consistent with values available in literature.

\section{Wyniki}

\subsection{HFRR}

Dla każdej zadanej temperatury pomiar właściwości smarnych wykonano trzykrotnie; obliczone wartości średnie podano w tabeli 5.

Table 5. HFRR test results

Tabela 5. Wyniki testu HFRR

\begin{tabular}{|c|c|c|c|c|c|}
\hline $\begin{array}{c}\text { Fuel/ } \\
\text { paliwo }\end{array}$ & $\begin{array}{l}\text { Tempe- } \\
\text { rature/ } \\
\text { tempera- } \\
\text { tura }\end{array}$ & MWSD & WS1.4 & $\begin{array}{l}\text { Avg. } \\
\text { film/ } \\
\text { film }\end{array}$ & $\begin{array}{l}\text { Avg. friction } \\
\text { coefficient/średni } \\
\text { wspótczynnik } \\
\text { tarcia }\end{array}$ \\
\hline & [degC] & {$[\mu \mathrm{m}]$} & {$[\mu \mathrm{m}]$} & {$[\%]$} & {$[-]$} \\
\hline ULSD & 60 & 315.0 & 320.0 & 83 & 0.176 \\
\hline Fat & 60 & 85.5 & 102.3 & 100 & 0.069 \\
\hline Fat & 75 & 86.5 & 104.2 & 100 & 0.078 \\
\hline Fat & 90 & 89.5 & 108.9 & 100 & 0.082 \\
\hline \multicolumn{6}{|c|}{$\begin{array}{l}\text { Where: MWSD - uncorrected mean wear scar diameter; } \\
\text { WS1.4 - corrected wear scar diameter/MWSD - nieskorygowana } \\
\text { średnia średnica śladu zużycia; WS1.4 - skorygowana średnica } \\
\text { śladu zużycia }\end{array}$} \\
\hline
\end{tabular}

Na rysunku 3 przedstawiono ślad zużycia dla oleju napędowego przy temperaturze $60^{\circ} \mathrm{C}$. Zmierzona średnica 320 $\mu \mathrm{m}$ jest porównywalna $\mathrm{z}$ danymi literaturowymi.

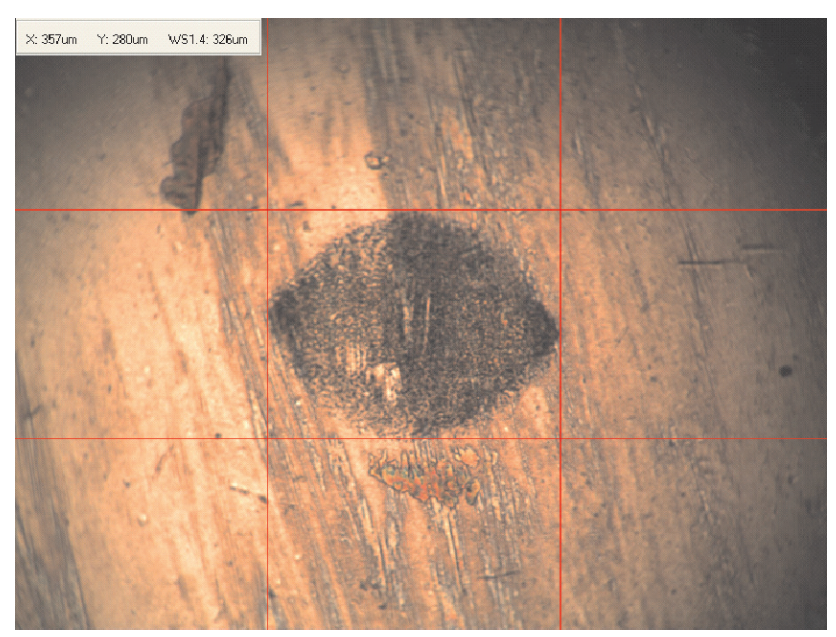

Fig. 3. Wear scar captured by digital microscope; ULSD at $60 \mathrm{degC}$ Rys. 3. Średnica śladu zużycia dla oleju napędowego przy temperaturze $60^{\circ} \mathrm{C}$

Zgodnie z przewidywaniami zmierzona średnica śladu zużycia dla tłuszczu zwierzęcego jest znacząco mniejsza (rys. 4). Wynik można tłumaczyć wysokim nienasyceniem tłuszczu - obecnością wiązań podwójnych, potwierdzonych przez wysoką liczbę jodową. Tłuszcz zwierzęcy zawiera około $10 \%$ tlenu, co poprawia jego właściwości smarne. Knothe i Steidley [11] wskazują na doskonałe właściwości smarne kwasów oleinowego i linolowego, potwierdzone brakiem wystąpienia śladu zużycia podczas przeprowadzonych testów. Dwa wymienione kwasy stanowią ponad 50\% składu tłuszczu zwierzęcego [12]. Różnice w smarności oleju napędowego i tłuszczu są bardziej widoczne, gdy porówna się 


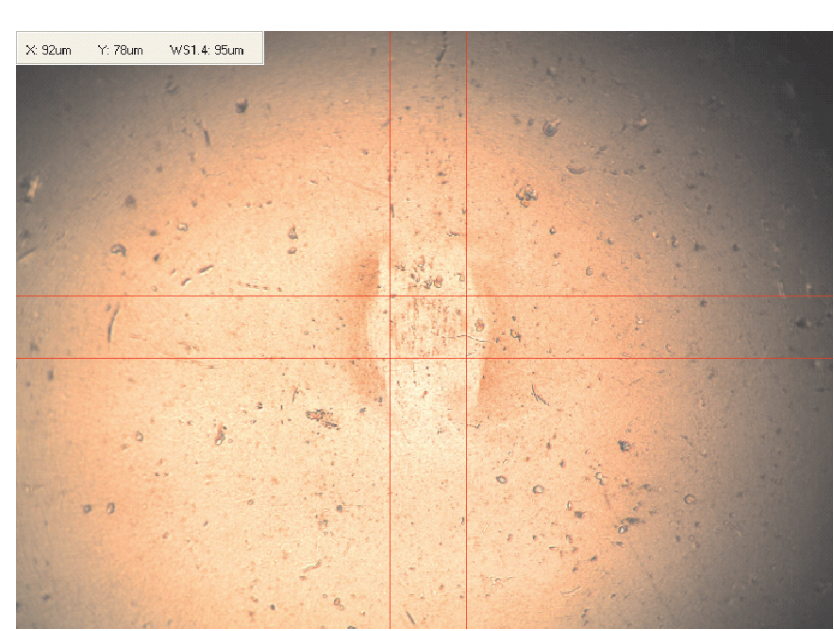

Fig. 4. Wear scar captured by digital microscope; Animal Fat at $60 \mathrm{degC}$ Rys. 4. Średnica śladu zużycia dla tluszczu przy temperaturze $60^{\circ} \mathrm{C}$ parametry filmu pomiędzy dwoma powierzchniami współpracującymi. Przy zastosowaniu tłuszczu zwierzęcego film powstaje już w piątej minucie testu, podczas gdy dla oleju napędowego pokrycie nie przekracza $85 \%$ podczas całego testu. Porównanie grubości filmu dla dwóch badanych paliw przedstawiono na rys. 5. Porównanie obejmujące pierwsze pięć minut testu przedstawiono na rys. 6. Lepsze właściwości smarne tłuszczu potwierdza również zmierzony niższy współczynnik tarcia (rys. 7).

Nie stwierdzono wpływu wyższej temperatury na właściwości smarne. Średnica śladu zużycia przy najwyższej temperaturze testu $\left(90^{\circ} \mathrm{C}\right)$ wzrosła o $7 \mu \mathrm{m}$, co przedstawiono na rys. 8. Współczynnik tarcia wzrósł o 0,013, co wskazuje na gorszą współpracę powierzchni.

Wyniki przeprowadzonych testów metodą HFRR są zbieżne z wynikami dostępnymi w literaturze. Udowodniono, że zanieczyszczenia obecne w thuszczu zwierzęcym, mieszczące się w zakresie przyjętej normy wewnętrznej, nie

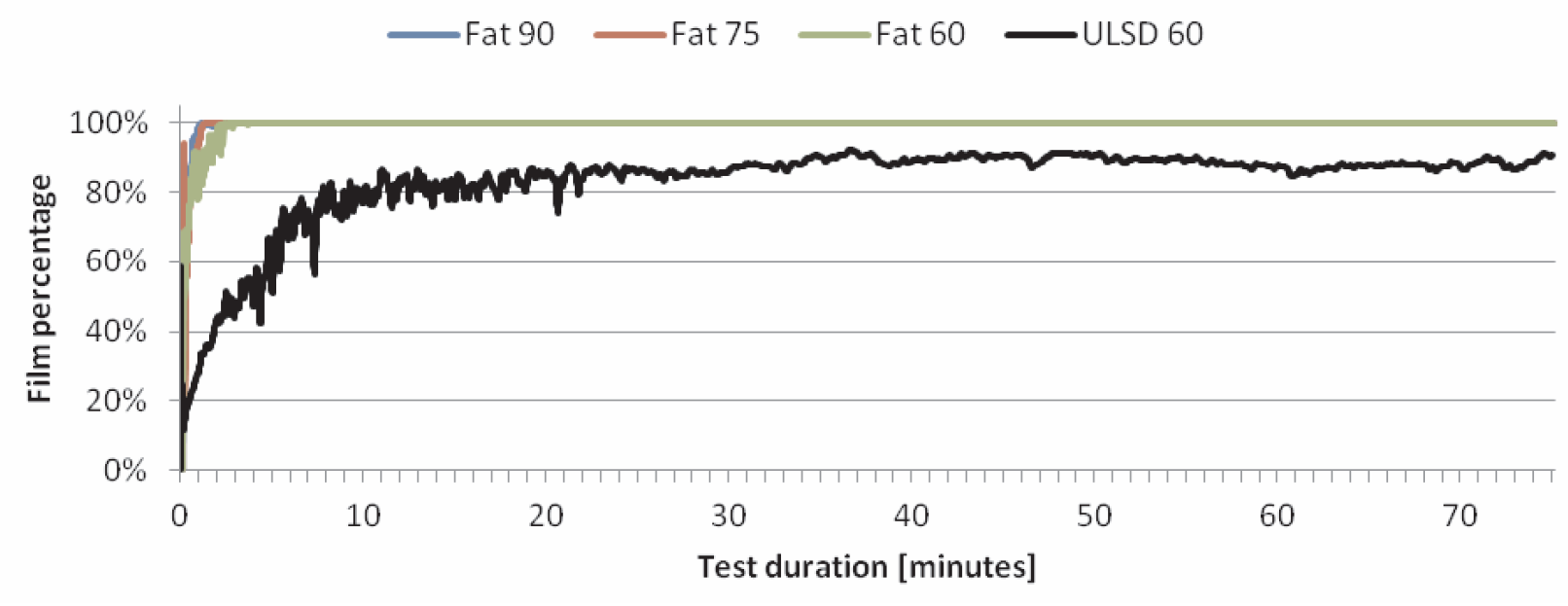

Fig. 5. Film coverage percentage for ULSD and animal fat at a range of temperatures Rys. 5. Udział filmu dla oleju napędowego i tluszczu przy różnych temperaturach

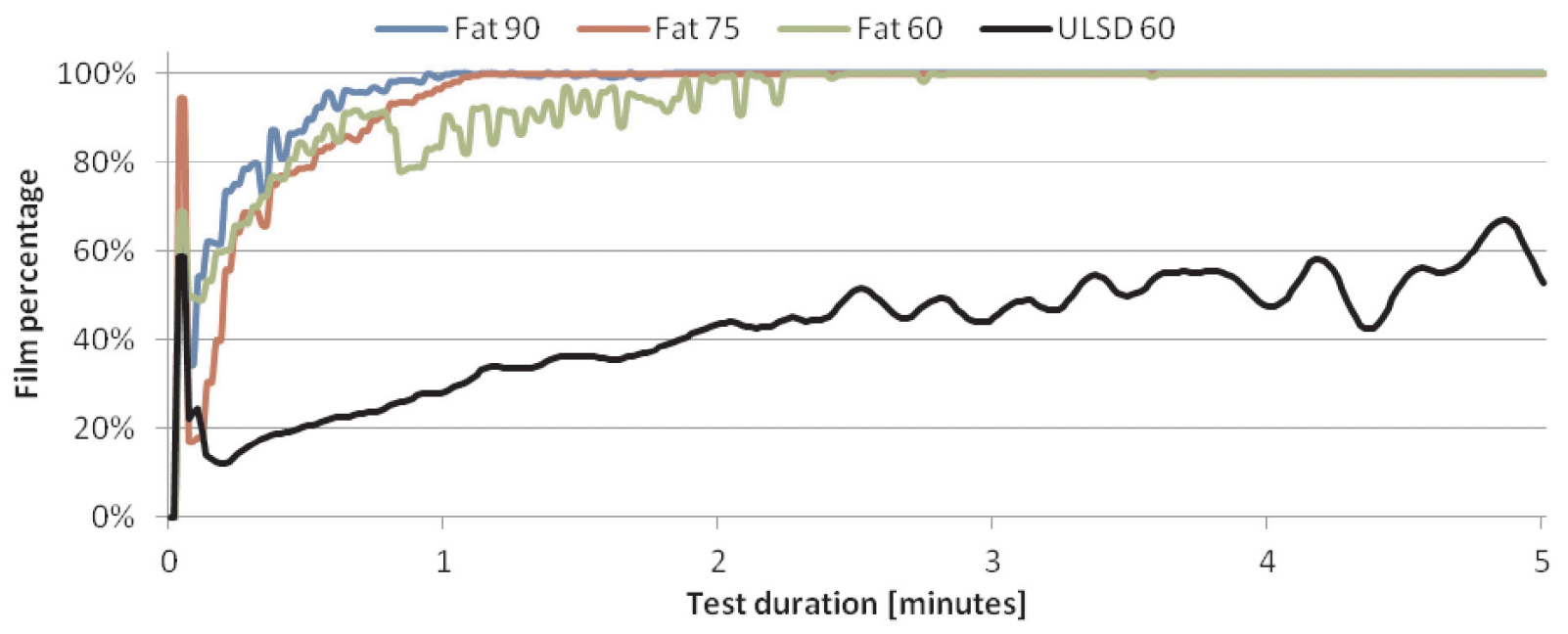

Fig. 6. Film coverage percentage for ULSD and animal fat at range of temperatures - first five minutes of the HFRR test Rys. 6. Udział filmu dla oleju napędowego i tłuszczu przy różnych temperaturach-pierwsze pięć minut testu HFRR 


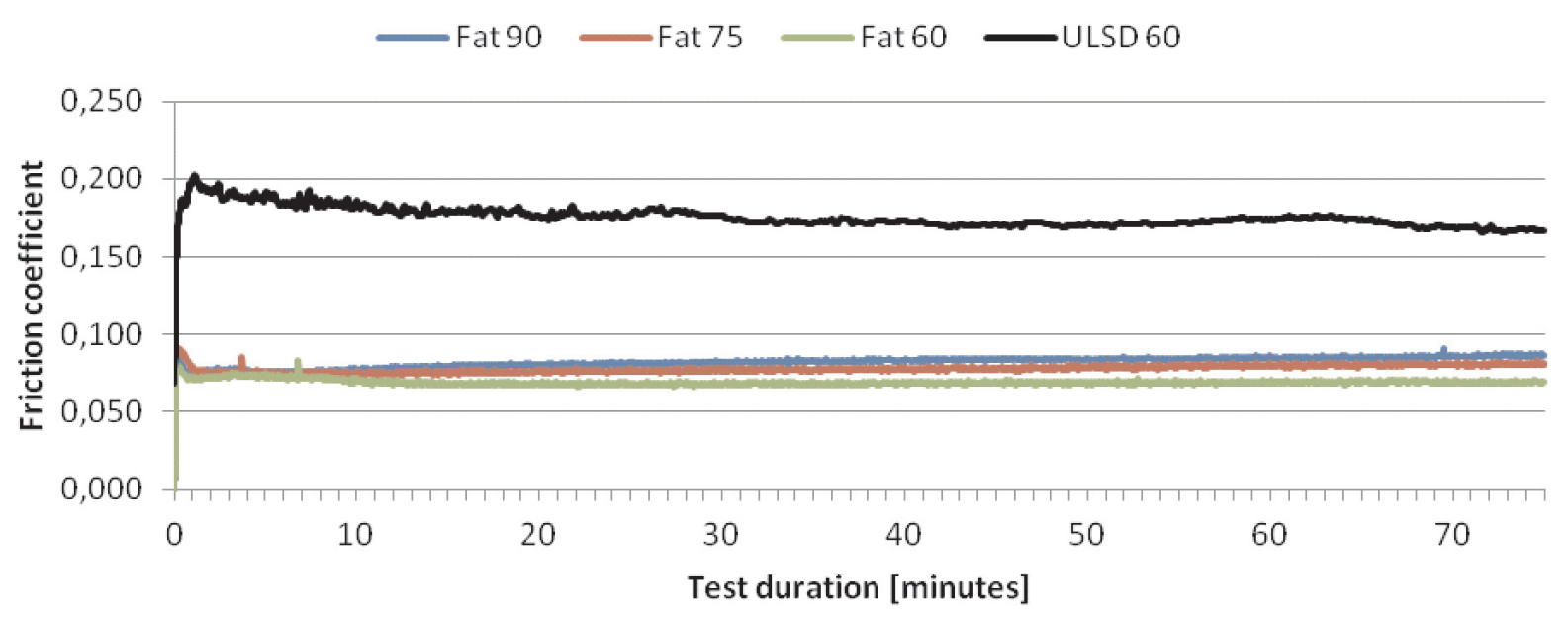

Fig. 7. Friction coefficient for ULSD and animal fat at range of temperatures

Rys. 7. Współczynnik tarcia dla oleju napędowego i tłuszczu przy różnych temperaturach

As expected wear scar diameter is significantly lower for animal fat than for diesel fuel. Measurement result is shown in Fig. 4. It can be explained by high unsaturation of animal fat - presence of double bonds, indicated by high iodine number. Animal fat contains 10\% oxygen that improves lubricity. According to Knothe and Steidley [11] oleic and linoleic acids have excellent lubricating properties, as no wear scar has been recorded. Those two components constitute more than $50 \%$ of animal fat composition [12]. Differences in lubricity of animal fat and ULSD are even more significant if film coverage is compared. For animal fat the liquid film is developed after less than 5 minutes of HFRR test whilst for ULSD it never exceeds $85 \%$ of coverage. Comparison of film thickness for both analysed fuels is given in Figure 5 and more detailed comparison focusing on the first 5 minutes of test is given in Figure 6. Better lubricity of animal fat can also be proved by lower friction coefficient; in all cases difference is significant. Comparison is given in Figure 7.

No significant impact of elevated temperature on lubricating properties has been detected. Wear scar diameter increased for highest test temperature (90 degC) by $7 \mu \mathrm{m}$; wear scar is shown in Figure 8 . Friction coefficient increased by 0.013 indicating slightly worse lubrication.

HFRR test results are consistent with those that could be expected from literature review. It proved that impurities present in fuel prepared for engine trials do not affect the lubricating properties. Lack of any significant increase of wear scar diameter for high temperature test ensures that fuel preheating, necessary for viscosity reduction, will not have negative impact on fuel pumps wear.

\subsection{Fuel pumps}

In total 12 pumps ( 2 sets) were tested, each used for approximately 1000 hours. The engine usually operated at high loads, above $75 \%$ of nominal power. Throughout the duration of trials no issues with fuel pumps were recorded. pogarszają właściwości smarnych. Brak znaczącego wzrostu średnicy śladu zużycia dla wyższych temperatur paliwa pozwala przypuszczać, iż jego podgrzewanie, mające na celu obniżenie lepkości, nie będzie skutkowało przyspieszonym zużyciem pomp wtryskowych.

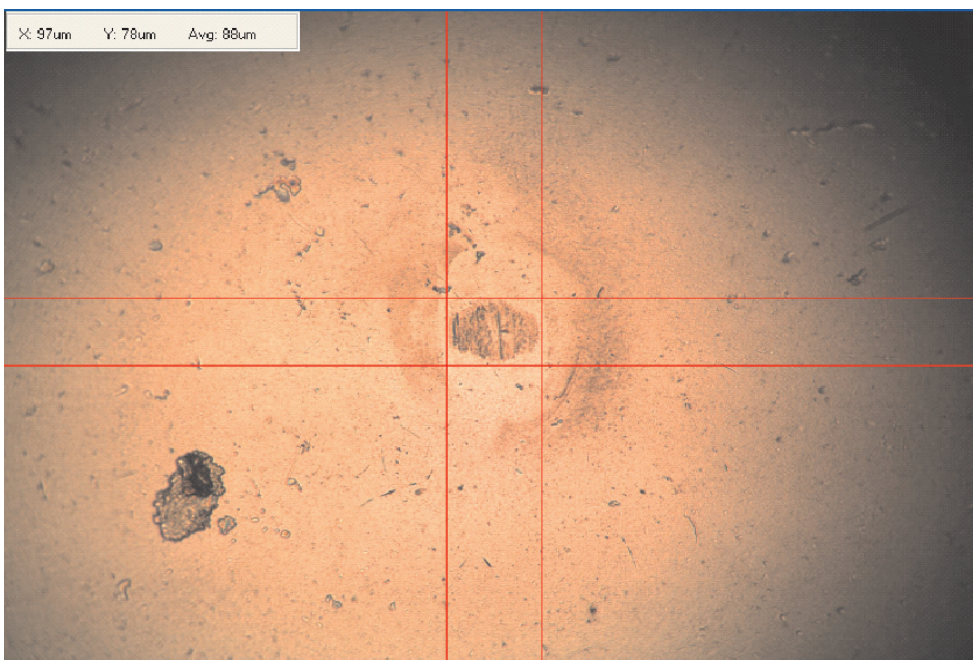

Fig. 8. Wear scar captured by digital microscope; Animal Fat at $90 \mathrm{degC}$ Rys. 8. Średnica śladu zużycia dla tluszczu przy temperaturze $90^{\circ} \mathrm{C}$

\subsection{Pompy wtryskowe}

Do badań użyto dwunastu pomp (2 zestawy po 6 sztuk). Wszystkie pompy testowano przez około tysiąc godzin. Silnik pracował pod wysokim obciążeniem (75\% mocy nominalnej). Podczas badań nie stwierdzono problemów eksploatacyjnych. Stanowi to potwierdzenie wyników testów laboratoryjnych i dobrych właściwości smarnych tłuszczów zwierzęcych. Zastosowany proces filtracji paliwa pozwolił na uzyskanie paliwa o właściwościach umożliwiających stosowanie go w silniku wysokoprężnym. Należy zaznaczyć, że stosowanie tłuszczów zwierzęcych w silnikach wyposażonych w system common rail wymaga dalszych badań i możliwych zmian w specyfikacji. 
It confirms laboratory test results and excellent lubricating properties of animal fat. The filtration process used for fuel pre-treatment is efficient enough to provide fuel with set of properties enabling trouble-free usage in the reciprocating engine fuel supply system. It has to be noted that implementation of these fuels for new common rail systems may require further investigation and specification alteration.

Fuel not complying with specification given in Table 1 has also been tested. Contamination with polyethylene, ash and insoluble impurities was noticeably higher. As a result, fuel pumps were damaged within less than 100 hours. Seal between plunger and guide was lost and fuel was leaking to the orifice below the fuel pumps, shown in Fig. 9 (picture has been taken through inspection window below fuel pump assembly; fuel droplets reflect flash light and are visible as group of white points surrounding the plunger). Fuel injection pressure could not be maintained at the required level, therefore it was impossible to operate engine at high load. Low injection pressure had an impact on the fuel spray resulting in increase of emissions of unburned hydrocarbons and carbon monoxide by approximately $300 \%$. Pumps were later dismantled and visual inspection of plunger surface confirmed wear signs caused by higher level of impurities present in the fuel. It has to be highlighted that damage occurred despite having standard fuel filter in place ( 5 micron cartridge).

\section{Conclusions}

The conducted research confirmed excellent lubricating properties of animal fat. Very small wear scar diameter for all checked temperatures encourages raising fuel preheating temperature and in consequence enabling viscosity reduction without concerns related to wear of fuel supply system elements. Test proved that fuel pre-treatment process, developed by the company partner, consisting of dual stage filtration is good enough to provide fuel that can be used in reciprocating engine without negative impact on fuel supply system. Laboratory tests have been confirmed by results obtained from research engine facility where two sets of fuel pumps withstand an endurance trail of more than 1000 hours. Engine trial confirmed that limits given in 'internal specification' were set up at correct level. Further research is required to develop specifications for more advanced fuel supply systems such as common rail.

Preheated animal fat can be used as an alternative fuel provided that appropriate filtration method is applied. Considering its low sulphur content it can be seen as interesting alternative fuel or lubricity enhancer in blends with conventional fuels.

\section{Acknowledgements}

The Technology Strategy Board of HM Government is gratefully acknowledged for part-funding of the Knowledge Transfer Partnership Project which made this work possible. John Pointon \& Sons Ltd. is thanked for part-funding the
Paliwo niespełniające wymogów normy podanych w tabeli 1 zostało również przetestowane. Poziom zanieczyszczenia polietylenem, popiołami i osadami był znacząco wyższy. Pompy wtryskowe uległy awarii w czasie krótszym niż 100 godzin. Doszło do uszkodzenia powierzchni tłoczka i korpusu pompy - w efekcie paliwo wyciekało do przestrzeni pod pompą. Wyciek przedstawiono na rys. 9 (fotografia wykonana przez okno kontrolne znajdujące

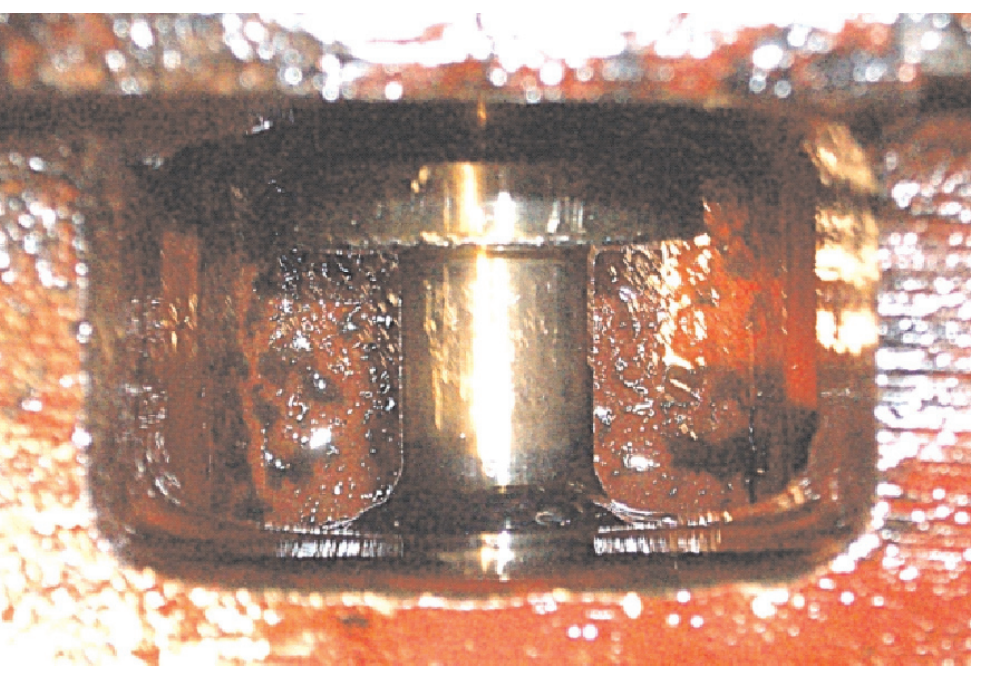

Fig. 9. Fuel leaking from damaged pump Rys. 9. Wyciek paliwa z uszkodzonej pompy wtryskowej

się w dolnej części korpusu pompy; krople paliwa odbijają światło lampy błyskowej i widoczne są jako grupa białych punktów otaczających tłoczek). Zaobserwowano znaczny spadek ciśnienia wtrysku, co uniemożliwiło pracę przy wysokim obciążeniu. Niskie ciśnienie wtrysku pogorszyło rozpylenie paliwa, powodując zwiększenie emisji węglowodorów i tlenku węgla o około 300\%. Po demontażu pomp zaobserwowano zwiększone zużycie powierzchni korpusu pomp i tłoczków, prawdopodobnie spowodowane zanieczyszczeniami obecnymi w paliwie. Należy zaznaczyć, że pompy uległy uszkodzeniu pomimo zastosowania sprawnego filtra paliwa (wkład $5 \mu \mathrm{m}$ ).

\section{Podsumowanie}

Przeprowadzone badania potwierdziły bardzo dobre właściwości smarne tłuszczów zwierzęcych. Mała średnica śladu zużycia zmierzona dla wszystkich badanych temperatur pozwala na przyjęcie podgrzewania jako właściwej metody obniżania lepkości, niemającej negatywnego wpływu na zużycie aparatury paliwowej. Wyniki dowodzą, iż proces produkcji i dwuetapowej filtracji wdrożony przez firmę John Pointon \& Sons Ltd. pozwala na uzyskanie paliwa o właściwościach umożliwiających zastosowanie go w silnikach spalinowych bez negatywnego wpływu na system zasilający. Wyniki badań laboratoryjnych zostały potwierdzone długoterminowymi (1000 godzin) testami pomp wtryskowych. Testy te potwierdziły, że limity obecności zanieczyszczeń zawarte w normie wewnętrznej zostały określone na właściwym poziomie. Dalsze badania są niezbędne do sformu- 
project, providing fuel samples and laboratory services. Some equipment used in this research was funded by Advantage West Midlands and the European Regional Development Fund as part of the Science City Research Alliance Energy Efficiency project.

\section{Nomenclature/Skróty i oznaczenia \\ CPO Crude Palm Oil \\ HFRR High Frequency Reciprocating Rig \\ SVO Straight Vegetable Oil \\ ULSD Ultra Low Sulphur Diesel \\ WSD Wear Scar Diameter}

Paper reviewed/Artykut recenzowany łowania specyfikacji dla paliw przeznaczonych do silników wyposażonych w systemy common rail.

Tłuszcze zwierzęce mogą być używane jako paliwa alternatywne pod warunkiem wprowadzenia odpowiedniego procesu przygotowania i filtracji. Ze względu na małą zawartość siarki tłuszcze stanowią interesujące paliwo alternatywne lub ulepszacz smarności w mieszaninach $\mathrm{z}$ paliwami konwencjonalnymi.

\section{Podziękowania}

Autorzy pragną wyrazić podziękowania dla The Technology Strategy Board of HM Government za częściowe ufundowanie programu Knowledge Transfer Partnership Project, w ramach którego prowadzono badania, oraz dla firmy John Pointon \& Sons Ltd. za współfinansowanie projektu, dostarczenie próbek paliwa i badania laboratoryjne. Sprzęt laboratoryjny użyty w badaniach został ufundowany przez Advantage West Midlands i Europejski Fundusz Rozwoju Regionalnego w ramach projektu „Science City Research Alliance Energy Efficiency Project”.

\section{Bibliography/Literatura}

[1] Lacey P.I., Mason R.L., Fuel Lubricity: Statistical Analysis of Literature Data. SAE, 2000. 2000-01-1917. ISSN, DOI: 10.4271/2000-01-1917.

[2] Anastopoulos G.L., Karonis E., Kalligeros D., Zannikos S.: Impact of oxygen and nitrogen compounds on the lubrication properties of low sulfur diesel fuels. Energy, 2004. 30(2-4): p. 415-426. ISSN: 0360-5442.

[3] Gomes H.O., Rocha M.I., da Silva R.C.F.: Diesel Fuel Composition Effect on Lubricity. SAE, 2003. 2003-01-3568. ISSN, DOI: $10.4271 / 2003-01-3568$.

[4] Knothe G.: The Lubricity of Biodiesel. SAE, 2005. 2005-013672. ISSN, DOI: 10.4271/2005-01-3672.

[5] Geller D.P., Goodrum J.W.: Effects of specific fatty acid methyl esters on diesel fuel lubricity. Fuel, 2004. 83(17-18): p. 23512356. ISSN: 0016-2361.

[6] Sulek M.W., Kulczycki A., Malysa A.: Assessment of lubricity of compositions of fuel oil with biocomponents derived from rape-seed. Wear, 2010. 268(1-2): p. 104-108. ISSN: 00431648.
[7] Piaszyk J., Wyszynski M.L., Tsolakis A.: Acidity of Tallow (Animal Fat) and Its Effect on Suitability of Tallow as Fuel in Electricity Generating Engines. Archivum Combustionis, 2010. 30(4): p. 471-480. ISSN.

[8] ASTM, Evaluating Lubricity of Diesel Fuels by the HighFrequency Reciprocating Rig (HFRR). 2011: D6079 - 11.

[9] PCS-Instruments. 2011 25/04/2011 ]; Available from: http:// www.pcs-instruments.com/hfrr/specimens/hfrr-specimens. shtml.

[10] Ruston-Paxman-Diesel, Ruston Instruction Manual - 6AR1 Vertical Diesel Engines. T546 ed, Lincoln: Ruston-PaxmanDiesel.

[11] Knothe G., Steidley K.R.: Lubricity of components of biodiesel and petrodiesel. The origin of biodiesel lubricity. Energy \& Fuels, 2005. 19(3): p. 1192-1200. ISSN: 0887-0624.

[12] Gunstone F.: Oils and Fats in the Food Industry. 2008: WileyBlackwell.
Miroslaw L. Wyszynski MEng, PhD, MSAE, MSIMP, PTNSS - Professor in the School of Mechanical Engineering at University of Birmingham, UK.

Prof. dr inż. Miroslaw L. Wyszynski-profesor na Wydziale Mechanicznym Uniwersytetu Birmingham, Wielka Brytania.

e-mail:m.l.wyszynski@bham.ac.uk

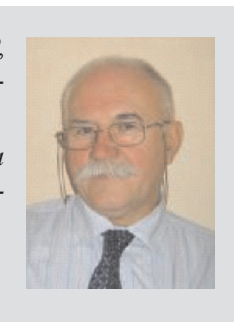

Jakub Piaszyk Jakub, MEng. - PhD research student in the School of Mechanical Engineering at University of Birmingham, UK.

Mgr inż. Jakub Piaszyk - doktorant na Wydziale Mechanicznym Uniwersytetu Birmingham, Wielka Brytania.

e-mail:j.piaszyk@bham.ac.uk 